The authors describe the structure and impact of facultyled intercultural field placements involving diverse groups of students.

\title{
New Learning and Teaching from Where You've Been: The Global Intercultural Experience for Undergraduates
}

\author{
A. T. Miller, Edith Fernández
}

When we began to design the Global Intercultural Experience for Undergraduates (GIEU) at the University of Michigan, we were looking to create a comprehensive program that would have a profound impact on the way students learned at the university and on the way faculty approached their students and taught. This was in addition to the mandate to both broaden and increase the level of "global" education at the university and to make sure that such a program drew in a far more diverse range of students and faculty than past efforts at experiential, community, or international learning. We wanted to be sure that our program had a positive impact on the community sites that were involved and a lasting impact on campus as well, building real and recognized skills among the student and faculty participants. All of these goals demanded a rigorous assessment regime and a complex and integrated set of activities that would build and develop from each other around a set of central field experiences.

\section{Program Description}

Each year GIEU funds eight to twelve faculty-proposed projects at sites both domestic and international. Each group is diverse and includes ten to fourteen undergraduates (GIEU student scholars) from across the university, 
along with one or two faculty members (GIEU teaching fellows). The groups visit culturally rich sites for three or four weeks during the summer months. For GIEU student scholars, this summer experience is a paid internship involving them with diverse peers in close local interactions. For the GIEU teaching fellows, it provides a stipend and the opportunity to work in creative and innovative ways with an interdisciplinary undergraduate team in the field. A wrap-around course for the students that begins in late February and ends in late September is complemented by a faculty seminar for all of the instructors. Prior to that, selection processes for both faculty proposals and student participants culminate in a December matching event at which the students selected for GIEU are matched with the GIEU experiences that will be offered over the coming summer. Because our emphasis is on intercultural learning, we try to deemphasize recruitment for particular field programs and encourage all participants to be open to both the domestic and international sites that might be available. The skills, habits of mind and behavior, openness, experiences, cooperation, and adaptability of both the students and the faculty members are cultivated through various exercises, community activities, reflective journaling, and small-team discussions.

GIEU is designed to have a positive and very broad impact on campus far beyond the individual participants. Faculty proposals must describe how the learning will come back to campus, and programs in intergroup relations and the Student Activities and Leadership office, along with the service-learning center, are involved in various phases of GIEU. Field sites change each year in order to permit new collaborations and a wider influence across campus. The students are drawn mostly from the first- and second-year classes so that their experiences can influence the activities they pursue during their remaining years on campus. Faculty may repeat the program once, although particular field experiences might repeat more than that if led by different faculty members. This allows academic departments and programs to cultivate a site or experience and develop it, with the hope that some will come to stand on their own outside of GIEU, as has already happened in a few cases.

The participants in GIEU over the years have been over half students of color, and the same has been true of the faculty participants. Students have come from all of our schools and colleges with undergraduate programs, and faculty have come from these units as well as from schools and colleges that offer only graduate degrees. Our most senior faculty (including a former university president) have participated, along with lecturers and research scientists. GIEU draws international and domestic students and faculty, both cosmopolitan and those lacking intercultural experience. Each year between 30 and 40 percent of GIEU students are on university-recognized financial aid, and we make a special outreach to first-generation college students, students in intensive academic programs (such as engineering or nursing) that have little space for electives, students of color, and male students, all of whom tend not to participate in experiential field learning programs. The course is offered as a university course so that the credit may be used in any 
major or college, and a GIEU experience meets some of the global, diversity, or field requirements for several academic programs. It also often feeds directly into our study-abroad, undergraduate research, service-learning, leadership, and intergroup relations programs.

\section{Program Evaluation Design}

Among the undergraduates we attempt to cultivate, measure, and study something that we are calling "global perspective," informed by the work of Kegan (1994) on mental organization and self-authorship, King and Baxter Magolda (2005) on intercultural maturity, and Bennett (2004) on intercultural sensitivity. We are quite intentionally stepping away from models of cultural or intercultural competence, which often emphasize the trifecta of knowledge, skills, and actions. We see ourselves as preparing both our students and our faculty for the unfamiliar, for work with strangers, for the ability to hit the ground running in places not their own and embrace new understandings with abilities to learn and act appropriately in context. Such personal capacity must be grounded in a mental perspective, an internal resource to be drawn on in habits of mind, rather than particular learned responses.

The concept of a global perspective is a complex one involving the ability to engage in critical self-reflection and to navigate an intercultural setting while acting in culturally sensitive and informed ways. By contrast, competence often implies focusing on the demonstration of skills per se, without any demonstrated self-awareness or reflection. Exploring someone's perspective, however, requires examining the underlying attitudes, beliefs, and cognitive structure that form the basis for using one's knowledge and skills. This approach includes components of the cognitive, interpersonal, and intrapersonal domains of development.

We draw on Kegan's holistic approach to these three domains (1994) to frame a global perspective as an important student learning outcome. King and Baxter Magolda (2005) built on this work to conceptualize how attention to each of these three areas can develop a mature capacity to consciously shift perspectives and behaviors into an alternative cultural worldview and to use multiple cultural frames. Individuals at the mature intrapersonal level of development have the capacity to create an internal self that openly engages challenges to one's views and beliefs and considers social identities (race, class, gender, and so on) in global and national contexts. Such individuals have the capacity to engage in meaningful reciprocal relationships with diverse others that are grounded in an understanding of, and appreciation for, human differences. Bennett (2004) studied the way people construe cultural difference and the varying kinds of development that accompany different constructions and termed this development "intercultural sensitivity." He proposes the Developmental Model of Intercultural Sensitivity, which recognizes that an increase in cultural awareness is accompanied by the development of empathy and 
improved cognitive sophistication. As a person's ability to understand differences increases, so does his or her ability to negotiate a variety of worldviews, a clear developmental marker. His continuum moves from stages defined as ethnocentric to those identified as ethnorelative.

In the GIEU program, an integrated global perspective is desirable because it helps one engage in critical consciousness and function at the optimal level of cultural sensitivity, continuous learning, and maturity to face the challenges and pressures of a multicultural environment and benefit from its opportunities. Our model for such a perspective includes four dimensions: (1) preferences for thinking and interacting, (2) intercultural relations, (3) intrapersonal awareness, and (4) global awareness. These dimensions are measured along a continuum from "monocultural global perspective" at the lower end to "integrated global perspective" at the higher end. Measures include the extent of one's ability to adopt others' perspectives, the degree to which one prefers complex explanations of behavior, the extent to which one seeks interactions with those different from oneself, one's awareness of the array of components that constitute one's own identity and how they affect others in various cultural contexts, and the degree of one's openness to and understanding of cross-cultural differences.

\section{Program Impact}

We have collected extensive data on the program in the first five years and have learned a great deal about what our faculty and students are getting out of this heavily integrated intercultural program. At the orientation and debriefing sessions, students fill out a pre- and post-field-experience survey designed by one of the authors (Fernández, 2006). Both before and after their field experience, faculty take the Intercultural Development Inventory, a fifty-item psychometric instrument developed by Hammer (1998), which measures six areas of Bennett's original Developmental Model of Intercultural Sensitivity (1993). We also interview faculty immediately after the project and then one year later to find out what impact the experience has had on their teaching and research. The students keep reflective journals throughout the experience, from which we (with their permission) and they (on our behalf) draw qualitative data. They write final essays at the end of the experience and are interviewed at graduation, often two to three years after they have participated in the GIEU program. We also seek evidence from or about the local field partners to assess if we are meeting our goal of benefiting these communities as much as we do our university constituents.

Overall, our quantitative measures show that on average, students and faculty show a greater interest and willingness to be involved in and face situations of cultural difference and conflict. Both groups also saw a corresponding drop in assertions of confidence in personal ability and knowledge in these areas. 
The cognitive items include nine that focus on attributional complexity (for example, "I think a lot about the influence society has on other people") and six that examine perspective taking ("I try to look at everybody's side of a disagreement"). Results indicate that students do not change much on these scales. For example, both before and after the experiences, they strongly agree with the statement about society's influence on other people, and they "agree somewhat" with the statement about trying to look at all points of view.

Interpersonal items include fourteen on global awareness (for example, "I often think about what I have in common with other people in the world") and eight on intergroup anxiety (reaction to "being laughed at for a minor mistake"), while the intrapersonal scale has six items ("I am aware of how people outside my own culture respond to my social identity"). Students show slight incremental growth on these items, but given the size of our sample and the short duration of the program, the growth has significance.

Our qualitative measures provide a much clearer sense of the longterm impact of the GIEU. Analysis of faculty writing and interviews reveal that GIEU has stimulated the self-awareness of our faculty teaching fellows as intercultural learners and brought them to value the importance of reflection for students as well as themselves. They show an enthusiasm for the world as an experiential classroom and speak directly of the challenges of working with students' various developmental levels and group dynamics. They gain new insights for curriculum and research and are actively sharing these insights with colleagues, and they have gained confidence in diverse undergraduate ability. Here are some comments from faculty participants:

I learned a tremendous amount about globalization and diversity. The growth of students was amazing, as was seeing that it was really possible. It was a true transformation. [It had] a big impact [on curriculum], giving me a battery of examples and cases. Very rich. (professor of sociology)

I have more tools to deal with these sorts of situations [conflict among diverse students], and the only resource in my life for this has been GIEU. (lecturer in Romance languages)

I am going to use [what I learned] in my training of instructors, especially nonU.S. instructors, about issues of diversity. (lecturer in Romance languages)

I have a new capacity to build an intercultural team between students. (instructor in women's studies and psychology)

I learned lots about the need to reflect on cultural experiences and learn about students and how they learn, about their limits and lack of experience. (professor of history) 
Student interviews, journals, and essays reveal common themes of examining their personal identities and stretching themselves while learning from group interactions, understanding privilege, and recognizing the limits of their own knowledge. Our students often reconnect to their field experience and host peoples through additional academic projects at the University of Michigan, exploring multiple identities and looking for additional opportunities. In many instances, GIEU serves as a gateway to intercultural career paths. The full impact of the program is clear in the following quotes taken from open-ended surveys conducted when the students graduate, usually two to three years after their participation in GIEU:

The GIEU program has definitely had an impact on my undergraduate years. Upon returning from my field site, I became involved with Project Community, a service-learning course. ... I used my own experiences as the basis for a lesson plan that I designed. I then traveled to various schools throughout the metropolitan area and presented my lesson to different classes. In addition, I served as a member of the Detroit Project planning team this past year. My involvement with GIEU furthered my interest in service-learning opportunities and challenged me to think critically about my surroundings. (2004 participant)

I can say without a doubt that the three weeks I spent ... in the summer of 2002 were among the most influential experiences of my time here at the university. Following the trip I added Latin American and Caribbean studies as a second major, studied for five months at the University of the Americas in Puebla, Mexico, and spent a month doing archival research in Cuba for my history thesis. (2002 participant)

My experience ... with GIEU started me on a whole new and unexpected path. I changed my major after that experience, I did my senior thesis research back in the same town that I had [visited] with GIEU, I have stayed in very close communication with [the faculty], and I am actually employed by them as a translator right now. I cannot imagine what my college experience would have been like without ... GIEU. (2004 participant)

One significant finding is that the impact of GIEU experiences increases over time for both students and faculty. For example, we discovered that our program was producing leadership for existing and new campus organizations that cross traditional student enclaves and develop broader networks of students. This outcome was not an initial goal of the program but has become increasingly evident as we gain insights from our graduation and long-term surveys. Similarly, faculty found that their involvement in GIEU had broader and unexpected consequences on their own development along the intercultural sensitivity spectrum. The GIEU grants and experiences have ended up affecting faculty teaching in courses on campus, their 
research questions and approaches, their engagement and insight into the lives and development of undergraduates, and their openness to intercultural, experiential, and interdisciplinary teaching and learning. Faculty often express appreciative surprise at the capacities of undergraduates, particularly in working with students from diverse majors, often far outside their fields of expertise.

\section{Explanation of Impact}

Through regression analysis we have determined that the aspects of the program that have more immediate impact are the reflective journals, the close interactions with faculty, and the diverse teams. In particular, students immediately appreciate and continually comment on how they become close to and work with people they would otherwise never meet. These same factors have a strong impact on faculty. We also examined the ways in which our program has differing effects on different types of students and faculty, with some of the biggest changes happening for the students most typical of the university (those from higher-income suburban backgrounds) and faculty with the most typical profiles (those who are most strongly discipline-focused). Because these are the groups least likely to find themselves in intercultural interactions on campus, it is not surprising that they are the most strongly affected by participation in an intercultural program. For other groups, GIEU also has an impact on attitudes and perspectives, though not as great. Participation in GIEU is, however, more likely to lead members of these groups (as opposed to the more "typical" group) to pursue opportunities on campus that build on their work in the program.

When we distinguish between the kinds of activities students engage in during particular field experiences, we find that the closer the interactions are with local constituents-for example, lodging with a local family-and the more the experience produces "intercultural anxiety" during field site activities, the greater the growth in developing an integrated global perspective. The student outcomes that showed complex thinking in intercultural situations were also enhanced by structured and reflective peer interactions across difference mediated by faculty members to acknowledge, surface, and process conflict. Service-learning activities on site were also significant in promoting cross-cultural interactions and learning, mainly because they provided context and purpose to the presence of outsiders at particular field sites. Students achieved the most positive learning outcomes and experienced the most development along the continuum when they were engaged in intimate interactions across lines of religion, participated in cultural rituals and events, and had opportunities for reflection with peers and faculty. This type of development deepened and was enhanced after students returned, as time and additional experiences offered further contexts for learning.

The outcomes for faculty were similarly enhanced by close interaction at the field site, reflection done together with the students, and the opportunity 
to compare outcomes with other faculty members engaged in similar projects. One year after the experience, these effects were enhanced, and insights were often greater than at the immediate debriefings and surveys. Faculty were often eager to repeat the experience a year or two later, to build on the insights gained and to encourage others to propose projects.

The mix of qualitative and quantitative assessment measures, both immediate and long-term, have been essential to understanding and refining GIEU. The results indicate that the program not only generates robust immediate results but also provides a set of experiences and tools that gain strength as participants find more and diverse contexts in which to apply their new knowledge and habits of mind. Some aspects of the program that generate initial resistance-such as administering cultural sensitivity measures to faculty members, pushing students into situations of intercultural anxiety, or expecting both to reflect frankly and in one another's presencehave all proved especially productive.

We recognize that there is a strong self-selection effect to programs like this that are competitive on both a faculty and a student level. We have not been able to survey as extensively a control group that has not been exposed to the GIEU program, but we have been able to compare between the various forty-five field experiences offered over the first five years of the program to discover the attributes that have the strongest positive outcomes. We trust that those data are valuable to individuals responsible for planning experiential higher education field activities in diverse communities.

\section{References}

Bennett, M. J. "Becoming Interculturally Competent." In J. Wurzel (ed.), Toward Multiculturalism: A Reader in Multicultural Education (2nd ed.). Newton, Mass.: Intercultural Resource Corp., 2004.

Bennett, M. J. "Towards Ethnorelativism: A Developmental Model of Intercultural Sensitivity." In M. Paige (ed.), Education for the Intercultural Experience. Yarmouth, Maine: Intercultural Press, 1993.

Fernández, E. "Developing a Global Perspective During a Study-Term Abroad." Ph.D. diss., University of Michigan, 2006.

Hammer, M. R. "A Measure of Intercultural Sensitivity: The Intercultural Development Inventory." In S. Fowler and M. Fowler (eds.), The Intercultural Sourcebook, Vol. 2. Yarmouth, Maine: Intercultural Press, 1998.

Kegan, R. In over Our Heads: The Mental Demands of Modern Life. Cambridge, Mass.: Harvard University Press, 1994.

King, P. M., and Baxter Magolda, M. B. "A Developmental Model of Intercultural Maturity." Journal of College Student Development, 2005, 46(6), 571-592.

A. T. MILLER is coordinator of multicultural teaching and learning at the Center for Research on Learning and Teaching and director of the Global Intercultural Experiences for Undergraduates Program at the University of Michigan.

EDITH FERNANDEZ is director of the Student Development Center and the Women's Resource Center at the University of Texas-El Paso. 